\title{
Harmonic Penetration Analyses for DC-Link Frequency Converter Drive Systems by Considering the Motor-Side Converter as an Ideal Current Generator
}

\author{
G. Gy. Balázs, I. Schmidt and P. Kiss \\ Department of Electric Power Engineering \\ Budapest University of Technology and Economics \\ Egry Jozsef u. $18 . \mathrm{V} 1 \mathrm{bdg} .3^{\text {rd }}$ floor, H-1111 Budapest (Hungary) \\ Phone/Fax number: +36 1463 2904, e-mail: balazs.gergely@ vet.bme.hu,
}

\begin{abstract}
Nowadays increasing attention turns to the harmonic penetration analysis of the alternating voltage network connected devices operating with pulse width modulation (PWM). The PWM operation causes high frequency current injection to the grid (at the frequency range: $1 \mathrm{kHz}$ to $100 \mathrm{kHz}$, depending on the power and the structure of the device). However, devices are now rolling out, that are infected by these current components, for example: power line communication (PLC) devices, smart metering devices, etc. It is very difficult to analyse such high frequency harmonic components with measurements. Therefore, the simulation analyses of the PWM devices harmonic penetration are revalued. These are cost efficient and fast.

This article is dealing with the harmonic penetration analyses of alternating voltage network connected DC-link frequency converters equipped with active rectifier. In our study we were focusing on the variable frequency drive (VFD) of squirrel cage induction motors (SCIM). Simulation models of the motor and a DC-link frequency converter were built in time domain. The main purpose of this paper is, to study whether the effect of the motor-side converter of the VFD and the motor can be neglected for the harmonic penetration analyses of the DC-link frequency converter.
\end{abstract}

\section{Keywords}

Power Quality, Harmonics, Frequency Converter, Computer Simulation, Time Domain Simulation

\section{Introduction}

Most of the AC network connected power electronic devices contain an internal DC-link. In these applications line-side converter connect the DC-link to the AC network, which is usually a diode rectifier. They only allow single-direction power flow and cause significant harmonic distortion. Instead of the simple diode rectifiers, active rectifiers are more widely spread that enable to fit the standards of the power quality. In some applications they allow bidirectional power flow. Usually the active rectifiers are operated with PWM modulation that injects high-frequency current harmonics into the AC grid. The high-frequency harmonics caused by lowpower devices are negligible, while high-power devices operated with low switching frequency inject highamplitude high-frequency current harmonics. This causes problems, because such devices are now rolling out, that are infected by these current components, for example: power line communication (PLC) devices, smart metering devices, etc. Moreover, the standards do not limit these current components.

DC-link variable frequency drive systems (VFD) or photovoltaic inverter units (PV) are good examples for AC network connected high-power devices. In the VFDs DC/AC converter (motor-side converter), while in the PVs DC/DC converter is connected to the internal DC-link. Usually these are operated with PWM modulation.

Increasing numbers of researches are dealing with the high-frequency current harmonic penetration of highpower drive systems. In several studies the DC-link connected DC/AC or DC/DC converters are substituted by voltage- or current generator. This approximation can significantly reduce the duration of the examination. Nevertheless none of the studies deal with the issue whether this approximation is correct considering the high-frequency current harmonics caused by the PWM operation. [1], [2], [3].

This paper is dealing with DC-link variable frequency drives that control squirrel cage induction motors. With simulation techniques we were examining the effect on the harmonic penetration of a VFD if the motor-side converter and the motor are modelled with an ideal current generator. Therefore we could find an answer whether the approximation is correct that is used by other studies.

\section{VFD models}

Based on differential equations we built the model and the control of a SCIM machine. In the models Park vectors were applied. The models were built in Matlab Simulink environment. Per-unit quantities were used, therefore the former equations are written in per-units. The block diagram of the implemented VFD models is shown on Fig.1. 


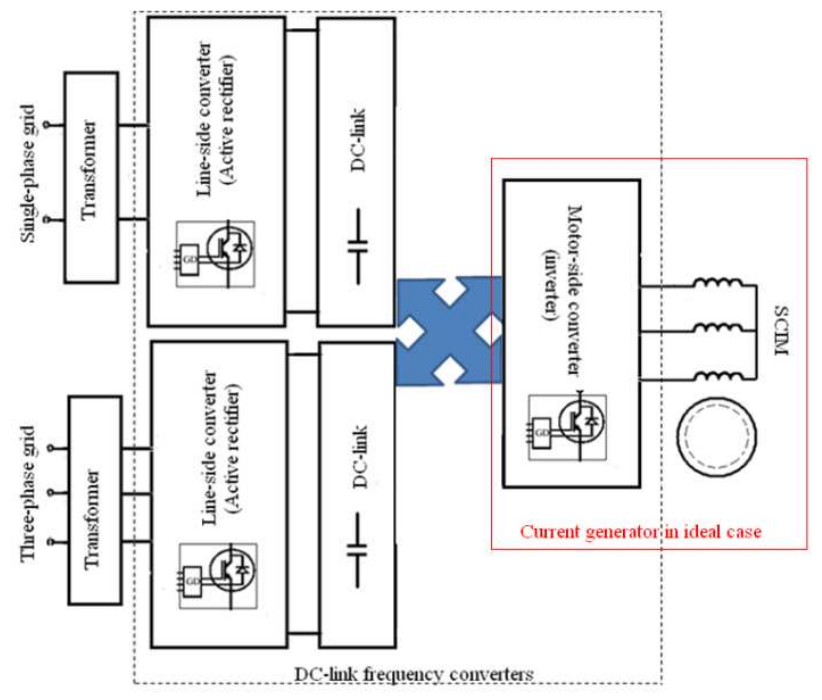

Fig.1. Block diagram of the VFD models

\section{A. Line-side converter models}

In the simulation the line-side converter was modelled as a bridge-type converter that enables bidirectional power flow (Fig.2,3). An inductance and a resistance representing the model of a transformer - were connected between the line-side converters and the grid. In our work we examined single- and three-phase grid connected VFDs respectively.

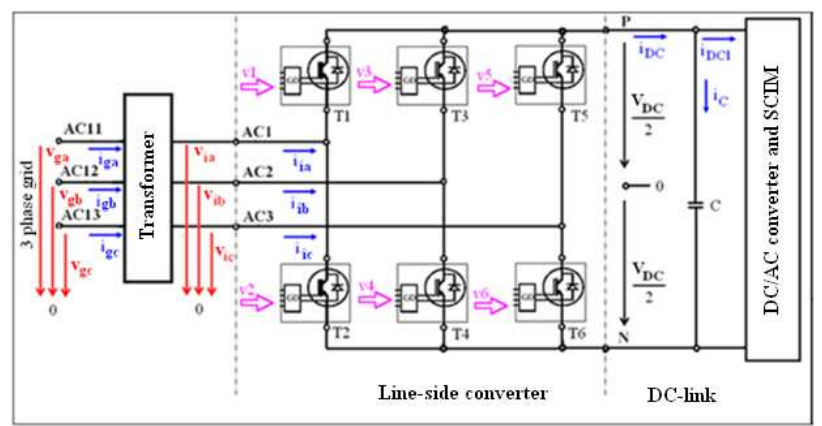

Fig.2. Schematic circuit diagram of a three-phase connected, bridge-type line-side converter

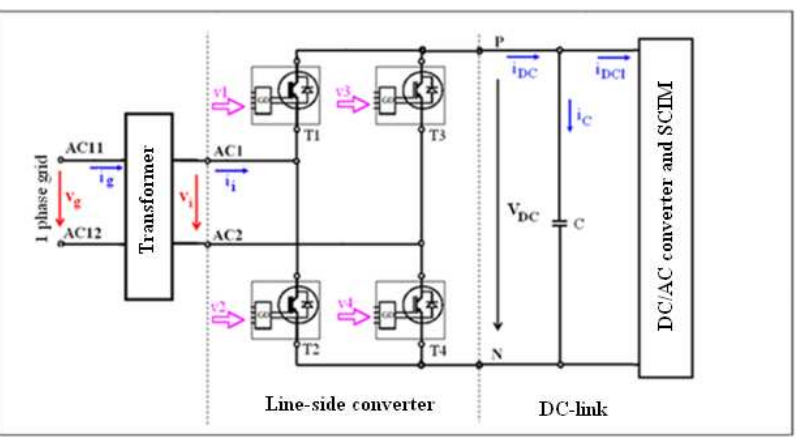

Fig.3. Schematic circuit diagram of a single-phase connected, bridge-type line-side converter

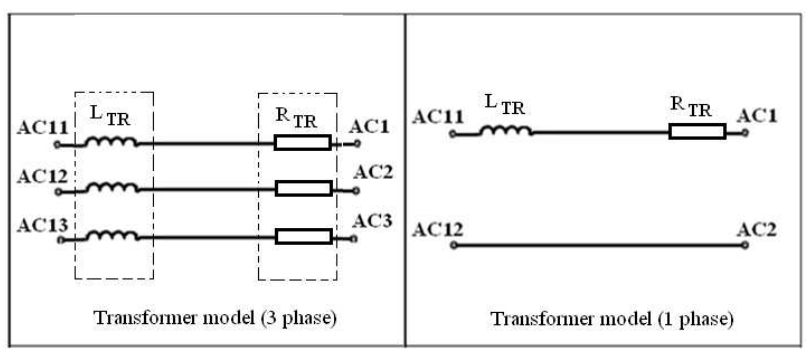

Fig.4. Transformer models

We built up the models of the single and the three phase grid connecter line-side converter of a VFD in the time domain. The inverter models consist of two main parts: the model of the power electronic circuit and the model of the control circuit. The three-phase grid connected units was modelled with Park vectors.

Based on the schematic circuit diagrams (Fig.2,3,4), the following differential equations can be written. (The overlines represent Park vectors, " $1 \mathrm{ph} / 3 \mathrm{ph}$ ": equation of single/three-phase connected circuits.) [4]:

- The equation of the transformer:

$1 \mathrm{ph}$ :

$$
\begin{array}{cl}
v_{g}=R_{T R} i_{g}+L_{T R} \frac{d i_{g}}{d t}+v_{i}, \quad \bar{v}_{g}=R_{T R} \bar{\imath}_{g}+L_{T R} \frac{d \bar{l}_{g}}{d t}+\bar{v}_{i} \\
i_{g}=i_{i}, \quad \bar{\imath}_{g}=\bar{\iota}_{i}
\end{array}
$$

- The power equations, can be written for both sides of a grid tie converter (lossless converter assumed)

$1 \mathrm{ph}: p_{i}=p_{D C} \Rightarrow v_{i} \cdot i_{i}=v_{D C} \cdot i_{D C}$

3ph: $p_{i}=p_{D C} \Rightarrow 3 \bar{v}_{i} \cdot \bar{l}_{i}=v_{D C} \cdot i_{D C}$

- The current of the DC-link:

$$
i_{D C}=i_{C}+i_{D C l}
$$

- The current of the buffer capacitor:

$$
i_{C}=C \frac{d v_{D C}}{d t}
$$

To fulfil the requirements of "network-friendly" equipments, the line-side converters need to have an adequate control circuit. In our study it was equipped with a cascade control (Fig.5,6.). This structure is commonly used. The primary control loop of the cascade is a DC-voltage-control $\left(\mathrm{v}_{\mathrm{DC}}\right)$ and the secondary loop is grid currents $\left(i_{\mathrm{ga}}, \mathrm{i}_{\mathrm{gb}}, \mathrm{i}_{\mathrm{gc}}\right)$ control. This structure guarantees a high power factor and an adequate grid current shape. In the control circuit the synchronization signal generator produces the fundamental of the grid voltage at the points of common coupling (PCC). Therefore the inverters were operated with sinusoidal current reference signal.

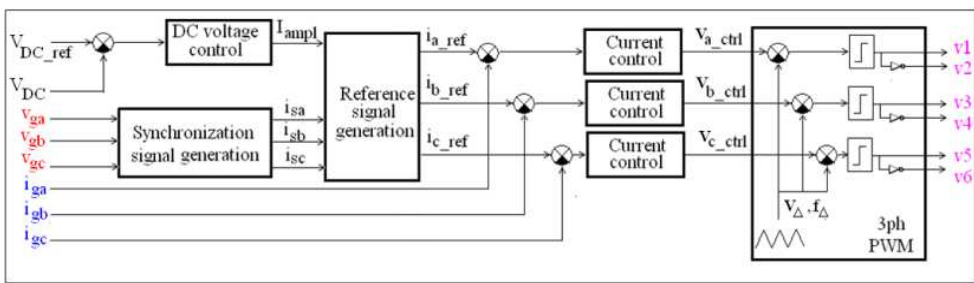

Fig.5. Control circuit block diagram of a three-phase grid connected converter 


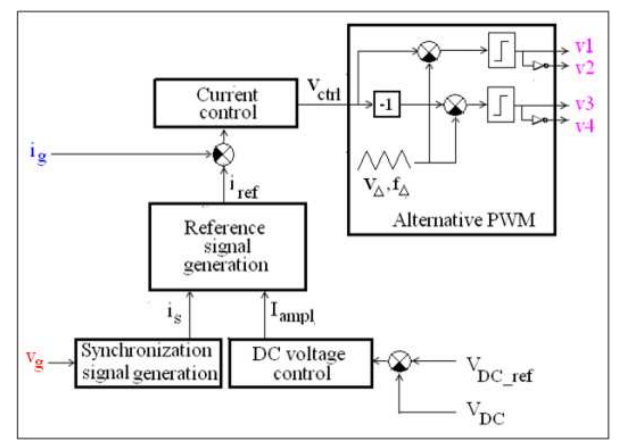

Fig.6. Control circuit block diagram of a single-phase grid connected converter

The line-side converters were operated by pulse width modulation (PWM) units. The "traditional" PWM method was implemented, in each phase a sine wave was compared with a triangular signal. Our simulation environment is capable for observing other PWM techniques. The single-phase connected inverters were operated by alternative PWM, because the current ripples can be reduced with this modulation technique.

- The operation of the single-phase connected line-side converter PWM modulation (ideal switching elements were assumed):

$$
v_{i}=\left\{\begin{array}{c}
+v_{D C} \text { if } v_{c t r l} \geq 0 \& v_{c t r l} \geq v_{\Delta} \\
-v_{D C} \text { if } v_{c t r l}<0 \& v_{c t r l}<v_{\Delta} \\
0 \text { for the rest cases }
\end{array}\right\}
$$

- The operation of the three-phase connected line-side converter PWM modulation (ideal switching elements were assumed, Fig.7. represents the characteristic waveforms of one phase):

$$
\begin{aligned}
& v_{i a}=\left\{\begin{array}{l}
+v_{D C} / 2 \text { if } v_{a_{-} c t r l} \geq v_{\Delta} \\
-v_{D C} / 2 \text { if } v_{a_{-} c t r l}<v_{\Delta}
\end{array}\right\} \\
& v_{i b}=\left\{\begin{array}{l}
+v_{D C} / 2 \text { if } v_{b_{-} c t r l} \geq v_{\Delta} \\
-v_{D C} / 2 \text { if } v_{b_{-} c t r l}<v_{\Delta}
\end{array}\right\} \\
& v_{i c}=\left\{\begin{array}{l}
+v_{D C} / 2 \text { if } v_{c_{-c t r l}} \geq v_{\Delta} \\
-v_{D C} / 2 \text { if } v_{c_{-} c t r l}<v_{\Delta}
\end{array}\right\}
\end{aligned}
$$

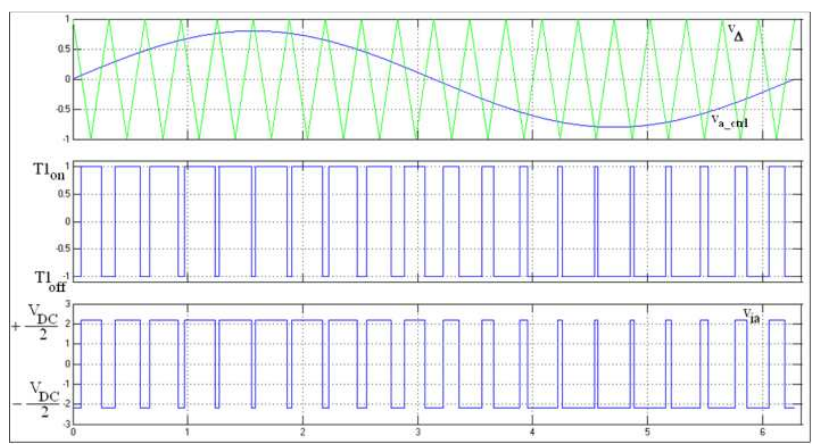

Fig.7. Characteristic waveforms of a three-phase PWM

\section{B. Motor-side converter and SCIM model}

In our simulations the squirrel cage induction machine was controlled by a two-level voltage source inverter. Nowadays this structure is the most widely used. The schematic circuit diagram of the motor-side converter and the motor is shown in Fig.8, that is similar to the three-phase grid connected line-side converter. The converter was operated by three-phase PWM that was mentioned in Chapter 2.A.

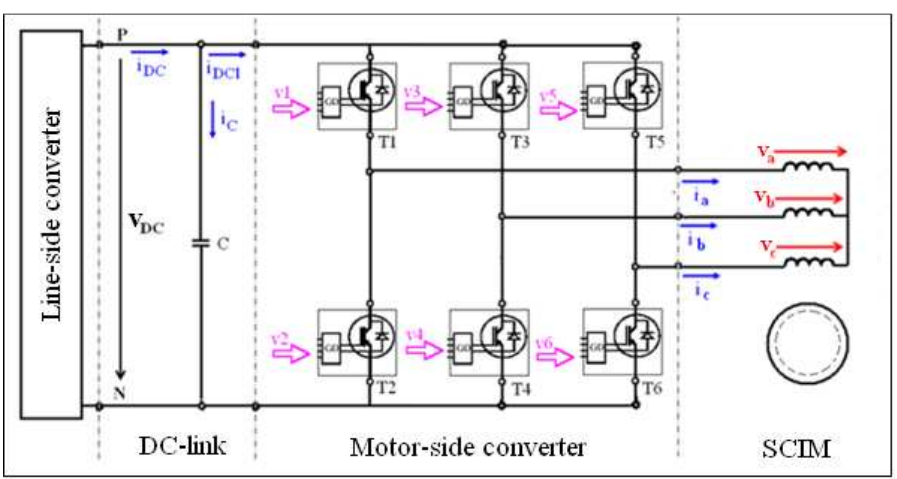

Fig.8. Schematic circuit diagram of the motor-side converter

The motor-side converter was equipped with speed control which was realized by field oriented current control (Fig.9.) [4]. This structure is commonly used. In the models the current control was performed in field coordinates. The speed, the rotor flux and the current component controllers were implemented with PI controllers. The coordinate system of the control method is oriented to the rotor field. Other control methods of the SCIM are also widely used, but this structure was sufficient for the harmonic penetration analysis.

In the control system of a real SCIM a machine model should be implemented that produce the position, the amplitude and the speed of the rotor flux. Our simulation model of the SCIM produces these quantities; therefore a separate machine model was not needed. The inputs of our SCIM model (Fig.8 red box) are: the phase voltage of the motor-side converter, while the model generates the motor speed $(\omega), \alpha$ and $\beta$ current components $\left(i_{\alpha}, i_{\beta}\right)$, and the position, the amplitude and the speed of the rotor flux $\left(\alpha_{\Psi_{\mathrm{r}}}, \Psi_{\mathrm{r},} \omega_{\Psi_{\mathrm{r}}}\right)$.

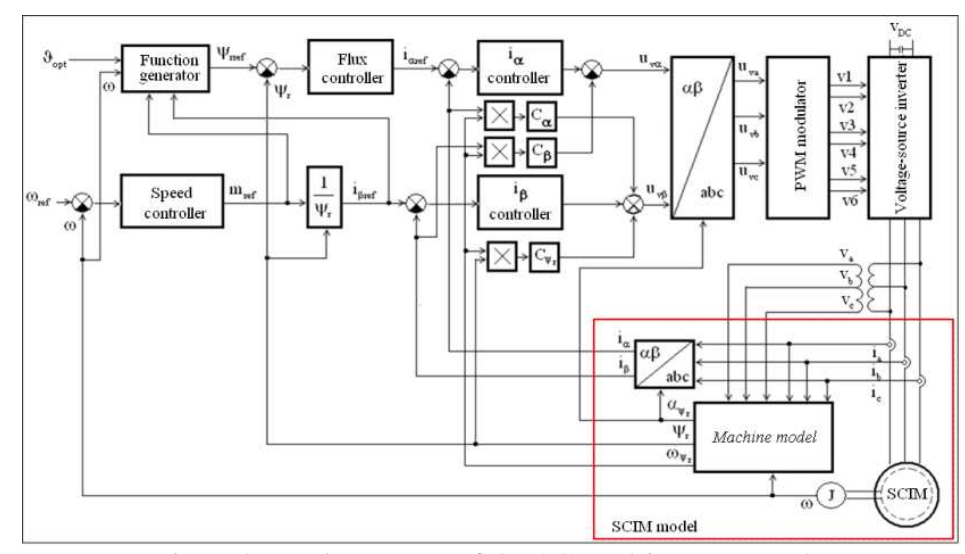

Fig.9. Control structure of the SCIM drive system [4]

The motor model was built based on the equivalent circuit of the SCIM (Fig.10.)

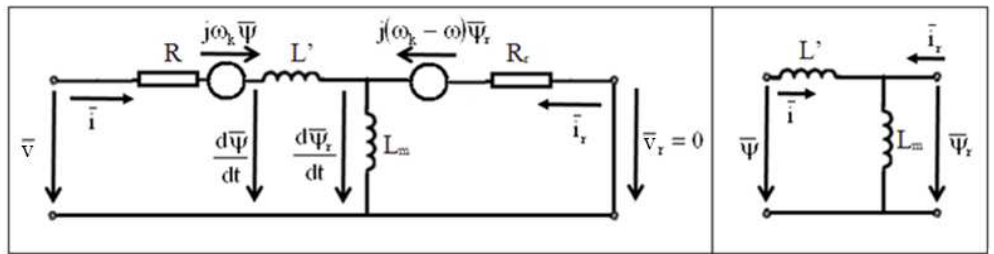

Fig.10. SCIM equivalent circuit for voltages and fluxes [4] 
Based on Fig. 10, the following equations can be written for voltages:

$$
\begin{array}{ll}
\bar{v}=R \bar{\imath}+\frac{d \bar{\psi}}{d t}+j \omega_{\psi r} \bar{\psi}, & \bar{\psi}=L^{\prime} \bar{\imath}+\bar{\psi}_{r} \\
\bar{v}_{r}=R_{r} \bar{l}_{r}+\frac{d \bar{\psi}_{r}}{d t}+j\left(\omega_{\psi r}-\omega\right) \bar{\psi}_{r}=0, & \bar{\psi}_{r}=L_{m}\left(\bar{\imath}+\bar{\iota}_{r}\right)
\end{array}
$$

The motor model was prepared by ordering these equations, and by using the following equations [5]:

$$
\omega_{r}=\frac{i_{\beta} R_{r}}{\psi_{r}}, \quad \frac{d \omega}{d t}=\frac{m-m_{t}}{T_{\text {in }}}, \quad m=\psi_{r} i_{\beta}
$$

Table 1 presents the applied quantities of the models. The line- and the motor-side converters were operated with

\begin{tabular}{|c|c|c|c|c|c|}
\hline & \multicolumn{2}{|c|}{ Per-unit quantities } & \multicolumn{3}{|c|}{ SI quantities } \\
\hline & $3 \mathrm{ph}$ & $1 \mathrm{ph}$ & $3 \mathrm{ph}$ & $1 \mathrm{ph}$ & \\
\hline $\mathbf{R}_{\mathrm{TR}}$ & \multicolumn{2}{|c|}{0.0161} & \multicolumn{2}{|c|}{0.005} & $\Omega$ \\
\hline $\mathbf{L}_{\mathrm{TR}}$ & \multicolumn{2}{|c|}{0.1595} & \multicolumn{2}{|c|}{$1.58 \mathrm{E}-04$} & $\mathrm{H}$ \\
\hline $\mathbf{C}$ & 0.8 & 5 & 0.0082 & 0.0511 & $\mathrm{~F}$ \\
\hline $\mathbf{V}_{\text {DCref }}$ & \multicolumn{2}{|c|}{2.2} & \multicolumn{2}{|c|}{968} & $\mathrm{~V}$ \\
\hline$V_{g(\mathbf{a}, \mathbf{b}, \mathbf{c})}$ & \multirow{2}{*}{\multicolumn{2}{|c|}{1}} & \multicolumn{2}{|c|}{440} & $\mathrm{~V}$ \\
\hline $\mathbf{f}_{\Delta}$ & & & & & $\mathrm{Hz}$ \\
\hline $\mathbf{R}$ & \multicolumn{2}{|c|}{0.02} & \multicolumn{2}{|c|}{0.0062} & $\Omega$ \\
\hline$T^{\prime}=L^{\prime} / R$ & \multicolumn{2}{|c|}{10} & \multicolumn{2}{|c|}{0.0318} & $\mathrm{sec}$ \\
\hline $\mathbf{L}_{\mathrm{m}}$ & \multicolumn{2}{|c|}{2} & \multicolumn{2}{|c|}{0.0020} & $\mathrm{H}$ \\
\hline $\mathbf{R}_{\mathrm{r}}$ & \multicolumn{2}{|c|}{0.02} & \multicolumn{2}{|c|}{0.0062} & $\Omega$ \\
\hline $\mathbf{T}_{\text {in }}$ & \multicolumn{2}{|c|}{62.8319} & \multicolumn{2}{|c|}{0.2} & $\mathrm{sec}$ \\
\hline
\end{tabular}
the same switching frequency.

Table 1: Quantities applied in the models

\section{Simulation studies and results}

After the model had been built, we performed simulation analyses for the whole VFD. First three-phase grid connected line-side converter was assumed, and then the simulation analyses were performed with single-phase grid connected line-side converter. The figures of Chapter 3 and 4 represent the case, when the converter is connected to the three-phase grid, but Table 2 summarizes the results of each case.

The whole drive system was analysed during acceleration, constant speed and braking. Fig.11. presents a simulation result for an SCIM:
I. flux evolution,
II. acceleration with maximum torque
III. field weakening
IV. constant speed
V. braking

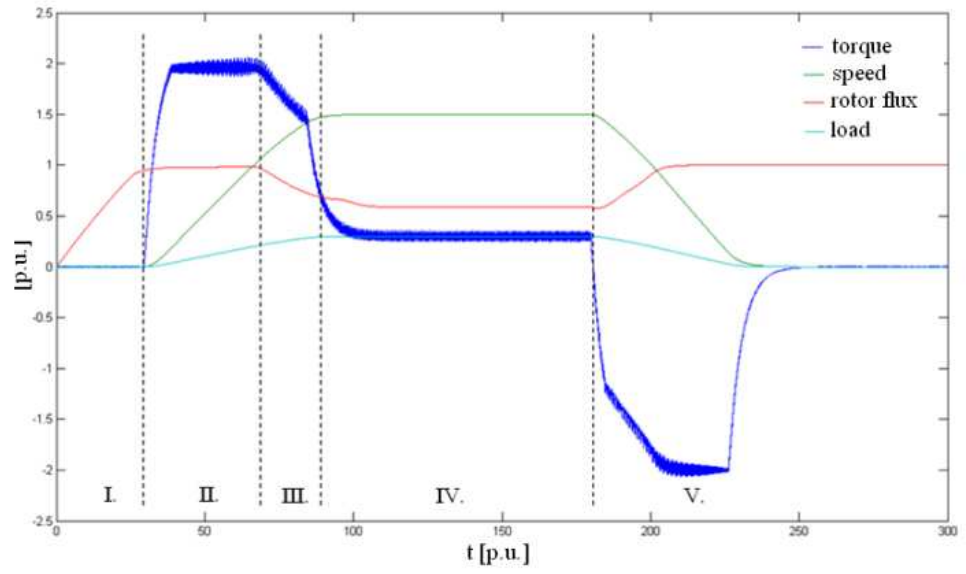

Fig.11. Time functions of a SCIM

During acceleration, constant speed and braking we observed the current load of the motor-side converter ( $i_{\text {DCl }}$ in Fig.2, Fig.3, Fig..8.). Then it was filtered by a low-pass filter and we received $i_{\text {DClf }}$ (Fig.12). The $i_{\text {DClf }}$ is not containing the high frequency components of $i_{\mathrm{DCl}}$.

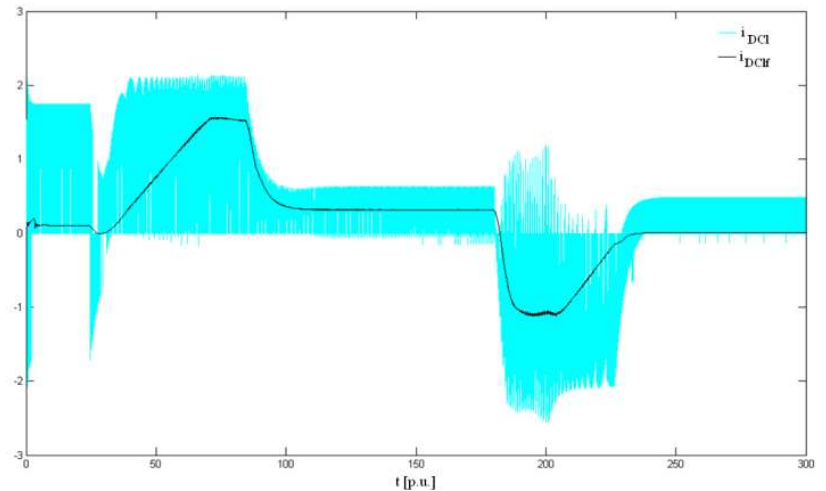

Fig.12 Current load of the motor-side converter

In the followings we assume realistic case, when the motor-side converter and the motor are considered as a realistic model (with $\mathrm{i}_{\mathrm{DCl}}$ ). On the other hand ideal case is assumed, when these are simplified as an ideal current generator (with $\mathrm{i}_{\text {DClf }}$ ), e.g. the red box in Fig. 1 is taken into account as an idealistic current generator. Fig.4. shows the consumed grid current of the VFD in one phase and the DC-link voltage while realistic $\left(i_{\mathrm{ga}}, \mathrm{v}_{\mathrm{DC}}\right)$ and ideal $\left(i_{\text {gaid }}, v_{D C i d}\right)$ cases were assumed. The figure presents the grid voltage as well $\left(\mathrm{v}_{\mathrm{g}}\right)$.

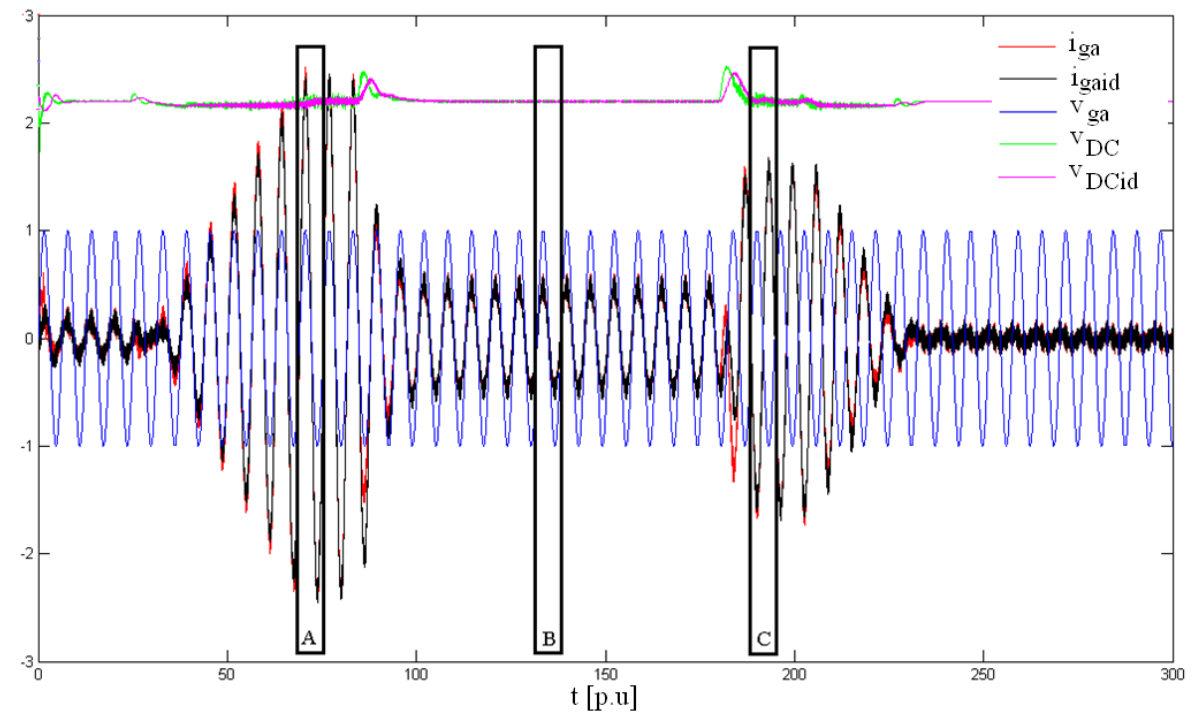




\section{Spectrum analyses}

Based on the time functions (Fig.13.) it is difficult to observe the differences between the two cases. Therefore spectrum analyses of the grid currents were performed up to the $115^{\text {th }}$ harmonic. One period was selected in acceleration (A), constant speed (B) and braking (C), the spectrum analyses were made in these periods.

(The figures show the spectrum results in phase ' $a$ '. We received approximately the same results in phase ' $b$ ' and 'c', and at single-phase connected line-side converter. The amplitudes of the fundamental currents are in the top right boxes.)

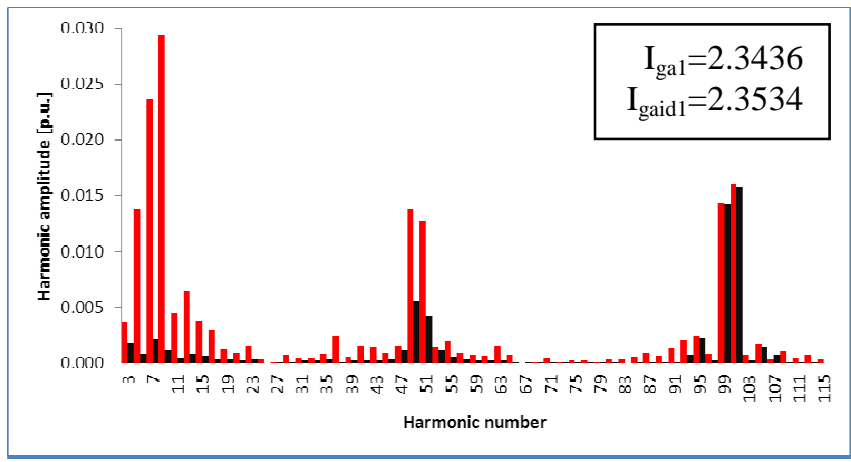

Fig. 14: Grid current spectra at acceleretion (period 'A') /red: realistic case, black: ideal case/

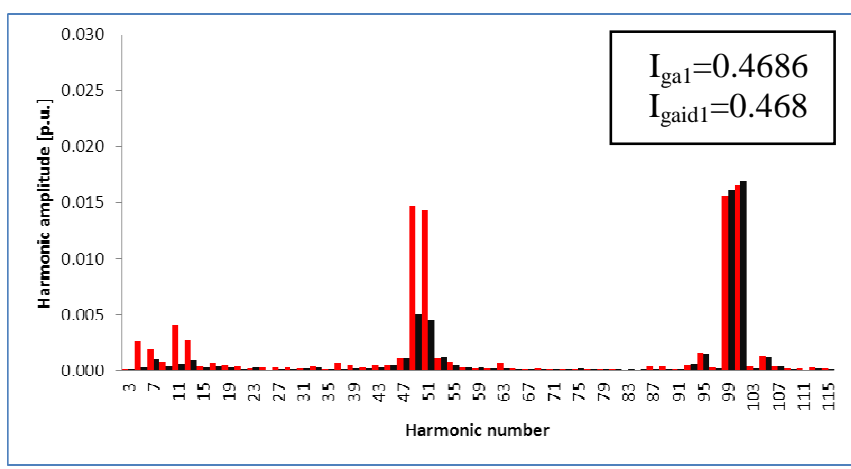

Fig.15: Grid current spectra at constant speed (period 'B') /red: realistic case, black: ideal case/

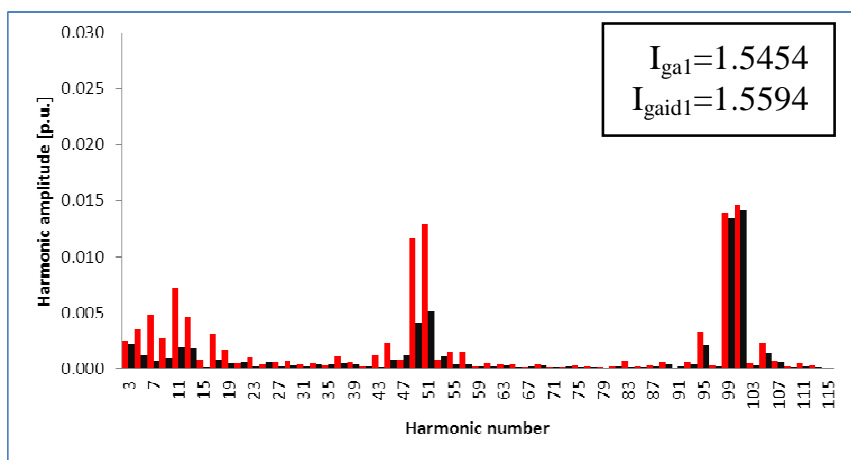

Fig. 16: Grid current spectra at braking (period ' $C$ ') /red: realistic case, black: ideal case/

A coefficient was defined to analyse the differences of the cases (where $v=1,3 \ldots 115$ : harmonic number, I: amplitudes).

$$
\Delta_{i g_{-} i g i d}=\frac{\sum_{v=1}^{115}\left(I_{g v}-I_{g v i d}\right)^{2}}{I_{g 1}^{2}}
$$

We calculated the coefficients in each phase while the VFD is connected to the three-phase grid (3ph) or single-phase grid (1ph). The results of Table 2 were received. It turned out minimal differences can be observed between the ideal and realistic cases.

Table 2: Comprehension of the calculated coefficients

\begin{tabular}{|c|c|c|c|}
\hline & \multicolumn{2}{|c|}{$3 \mathrm{ph}$} & $1 \mathrm{ph}$ \\
\hline \multirow{3}{*}{$\begin{array}{c}\text { acceleration } \\
\text { (A) }\end{array}$} & phase 'a' & $0.03 \%$ & \multirow{3}{*}{$0.03 \%$} \\
\hline & phase ' $b$ ' & $0.02 \%$ & \\
\hline & phase 'c' & $0.04 \%$ & \\
\hline \multirow{3}{*}{$\begin{array}{l}\text { constant } \\
\text { speed } \\
\text { (B) }\end{array}$} & phase 'a' & $0.10 \%$ & \multirow{3}{*}{$0.01 \%$} \\
\hline & phase ' $b$ ' & $0.10 \%$ & \\
\hline & phase 'c' & $0.10 \%$ & \\
\hline \multirow{3}{*}{$\begin{array}{l}\text { braking } \\
\text { (C) }\end{array}$} & phase 'a' & $0.02 \%$ & \multirow{3}{*}{$0.01 \%$} \\
\hline & phase 'b' & $0.01 \%$ & \\
\hline & phase 'c' & $0.01 \%$ & \\
\hline
\end{tabular}

\section{Conclusions}

Based on the simulation results, it turned out, the effect of the motor-side converter and the motor can be neglected for the harmonic penetration simulation analyses of the DC-link frequency converter equipped with active rectifier. These parts can be considered as an ideal current source. With this approximation and simplification the simulation time is significantly reduced.

\section{References:}

[1] P. Kiss, G. Gy. Balázs, A. Dán, I. Schmidt: The Application of the Double Domain Simulation with PWM Controlled Locomotives: 14th International Conference on Harmonics and Quality of Power, (ICHQP) Bergamo, Italy, 2010

[2] J. Michalík, J. Molnár, Z. Peroutka: Single-Phase CurrentSource Active Rectifier: Control Strategy under Distorted Power Supply Voltage, Electrical Review, Vol.7 2009.

[3] V. Blahník, J. Žák, T. Komrska Z. Peroutka: Compensation of Low-Frequency Disturbances for Traction Converter with Medium-Frequency Transformer for Multi-System Suburban Units, 14th International Power Electronics and Motion Control Conference (EPE-PEMC), Ohrid, Macedonia, 2010

[4] I. Schmidt, Gy. Vincze, K. Veszprémi: Electrical Servoand Robot Drives. Budapest, Hungary, 2000 (in Hungarian)

[5] G. Gy. Balázs, "Controlling of Four-Quadrant Converters Especially in Electric Vehicles" $\mathrm{PhD}$ dissertation, BUTE, Budapest, Hungary (2012) 